\title{
About the Quality of Maps
}

\author{
Georg Gartner \\ Institute of Cartography \\ Vienna Univ. of Technology \\ Karlsgasse 11 \\ A-1040 Vienna, Austria \\ gartner@ekrms1.tuwien.ac.at
}

INTRODUCTION

"Although the WWW meets most of the needs of the 'new cartography'... the cartographic response has focused on a missing 'quality'..."

"This concern with graphic quality arises from subjective criteria of good and bad that are often not explicitly stated, even among cartographers."

GENERAL CONCEPTS OF QUALITY
Periodically throughout history, advances in technology have affected cartography. Some current forces for change in cartography are interactivity, multimedia, computer-animation and the Internet. Cartographers complain of a missing quality in the maps associated with this new technology. This paper examines the meaning of quality in cartography. It is argued that only when terms such as quality are understood in a larger, external context can the goal of map-making-making better maps - be pursued. This includes esthetical and cognitive aspects as well as aspects of communication, GIS and geographic visualization.

\section{Keywords: Map quality, Internet cartography, Multimedia cartography}

$\mathrm{T}$ he Internet has brought about a major change in how maps are distributed. Analogous to the invention of printing, the capabilities of the Internet for map reproduction and delivery can be seen as a revolution (Peterson 1995, 1997). Although the WWW meets most of the needs of the "new cartography" (Taylor 1994, Müller 1997), such as enabling interactive and dynamic maps and using technologies associated with multimedia, the cartographic response has focused on a missing "quality" (Dickmann 1997, Crampton 1997, Harrower et. al. 1997), in particular, the lack of graphic quality and resolution.

This concern with the graphic quality of computer-produced maps is not new in cartography. Concerns were raised in the 1960's and 1970's about early computer maps, with similar reservations still expressed about maps produced by GIS software. This concern with graphic quality arises from subjective criteria of good and bad that are often not explicitly stated, even among cartographers. Numerous ideas have emerged in the cartographic literature about how to improve maps, without specifically defining the concept of quality in relation to maps. The increased use and the further development of technologies like interactivity, multimedia and computeranimation, have led to new cartographic expressions and products and intensified the questioning of map quality. Problems arise when these new products and expressions are judged using the former definitions of quality.

This paper deals with the meaning of quality in cartography. The first section will consider the concept of quality developed in other areas, particularly philosophy and economics. The second part focuses on the more general meaning of the term quality, and the consequences that must be considered when thinking about the quality of maps. A synoptic interpretation of the importance of understanding quality is given in the conclusion which analyzes quality in relation to major trends in cartography, particularly developments like interactivity, multimedia and map distribution through the Internet.

The problem of defining quality is neither new nor especially a cartographic task. The meaning of quality has been examined, in general terms, by philosophers and more specifically through such economic concepts as product value. Some of these concepts can be seen as relevant to the question of the "quality of maps" and thus have an impact on the way cartographers think about quality. 


\section{Philosophical definitions of quality}

The general branch of philosophy that is concerned with quality in terms of "value" is called axiology. Axiology is commonly divided into ethics and aesthetics. Ethics focuses, first of all, on the value of "goodness" and "badness," as, for instance, in human activities. Aesthetics deals with the worth of "beauty" and "ugliness." Both ethics and aesthetics can be seen as determinants in the development of the general meaning of quality in every human being, including cartographers and map users. Every perception or feeling of "good" or "beautiful" can be seen as being a result of these conceptions.

Both ethics and aesthetics are important in cartography. Ethics is important because it is concerned with determining the value of various human actions, and why they have these values. The mentioned values and ethical convictions have to be seen as resulting from the judgment of the action by other subjects. Therefore, ethics can be seen as the dynamic and permanently changing result of many judgments of actions of various subjects by various persons. Because of the decisive role of those who are judging the actions, the social, cultural and spatial milieu of these people influence the result. Examples of the dynamics of ethical values can be found in our daily life. For instance, corporal punishment was once thought to be necessary in the education of children. Such punishment is no longer considered to be a part of a "quality education."

Furthermore, ethics tries to analyze and explain the conditions and determinants that influence the subjects, their actions and the ethical judgment of other subjects. In other words, our understanding of a "good map" is, like other ethical judgments, a result and an expression of our ethical understanding, which is, aside from other determinant aspects, the result of the actions (maps) of previous subjects (cartographers).

In this context, an understanding of ethics must consider the relationships between the internal and external aspects and influences of a subject. As McHaffie (1990) has pointed out with reference to cartography, "... it is difficult to imagine how cartographers can create ethical standards which do not in some way refer to values created outside the discipline." This idea has been expanded by Monmonier (1991), who has argued, that every action of a cartographer (a map) has to be seen as a "... major strand in the web of social relations by which cartographers project their values into the world." Harley states that "Each map is a manifesto for a set of beliefs about the world" (Harley 1991, p.13). This leads to Crampton's (1995) idea of a dialectical relationship between internal and external aspects of a spatial analysis system. Ethics can then be seen as the source of the cartographer's "moral authorization" in terms of the role of cartography in the world, as well as the way in which the world is represented in maps.

Aesthetics is important in explaining why we "feel" beauty, because it expresses quality in both sensory and non-sensory terms. Quality, in the aesthetical sense, includes both a judgment about the object and a judgment about the perception of the object. A statement like "this map is beautiful" is not only an opinion about the map but about the perception of the person who makes this statement. When evaluating the aesthetical quality of maps, it is necessary to consider this relationship.

Besides these aesthetic / ethical-oriented distinctions, there are more value-oriented distinctions of quality that are both useful and plausible. To illustrate, two generally different ways of understanding quality can be considered. From a more idealistic view point, an absolute value exists that can only be reached theoretically, but should be aspired to in any case. Examples of this view can be found from Plato ("idea of the good") to Kant
"... ethics and aesthetics can be seen as determinants in the development of the general meaning of quality in every human being, including cartographers and map users."

". . our understanding of a "good map" is. . . a result and an expression of our ethical understanding. .."

"Quality, in the aesthetical sense, includes both a judgment about the object and a judgment about the perception of the object." 
"If an absolute, ... value of quality for a map exists, and this quality is aspired to, then every map has to be judged by that value, ... If, ... the quality of a

map means that a map only must meet the needs of a certain user in a specific situation, maps created by the new technologies can better meet this requirement."

"The judging of the quality of maps is rarely founded in rational reasoning but is the result of just this meta-entity, a pre-intellectual awareness of sorts." ("quality as a form of perception"). The more realistic / pragmatic view of quality assumes that every value (quality) has to be seen in its relation to the being (reality), i.e., in relation to time, space and the participants (involved or acting persons). In contrast to the idealistic understanding of quality, the proponents of the pragmatic/realistic understanding do not believe that an absolute value exists (as in "this map is good/beautiful"). Rather, they argue that the understanding of quality not only changes over time, but also with the judging person and his/ her (social, cultural, intellectual) background. While those of the idealistic viewpoint believe that an object, such as a mountain, retains its quality even if it is not seen for a thousand years, the proponents of the realistic view assume that the quality of the object can only be judged in its relationship to an individual perception.

Similar idealistic and realistic distinctions can be applied to cartography as well. For example, the system of hypsometrical representation of terrain by Imhof (1969) - "as natural-like as possible" - uses an absolute concept of quality. The development of cognitive ideas in cartography leads to an increasing application of the realistic definition of quality. These different positions can also be found in the discussions of quality and maps on the Internet. If an absolute, highest value of quality for a map exists, and this quality is aspired to (for example, by improving the graphical quality), then every map has to be judged by that value, including maps on the Internet. If, on the other hand, the quality of a map means that a map only must meet the needs of a certain user in a specific situation, maps created by the new technologies can better meet this requirement.

A pragmatic definition of quality as value, as suggested by Pirsig (1974), has been established in economic theories (Dobyns \& Crawford-Manson 1994). Pirsig's definition of quality as the harmony of "subject and object" can be seen as a way of understanding the meaning of quality in maps. The analogous harmony of maps, the object, and the mental image of reality, the subject, can only be achieved by objects (maps) meeting a "pre-intellectual awareness" (Pirsig 1974, p.240). In Pirsig's sense, as interpreted by DiSanto \& Steele (1990), quality is relative. Pirsig argues that quality cannot be defined as the "rational self" of a product, but must also include the cause, source and creator of subjects and objects (DiSanto \& Steele 1990, p.183). In this sense, different people will judge quality differently. The quality of a particular object / subject-situation (such as driving a motorcycle through America) is neither explainable nor understandable with mind or with matter, but as a third entity, that formulated by Pirsig "... as the parent, the source of all subjects and objects." In this sense, an objective understanding of quality is not possible because quality is experienced as a meta-entity, a pre-intellectual awareness.

This definition of quality seems to be a plausible explanation for cartographic interpretations. The judging of the quality of maps is rarely founded in rational reasoning but is a result of just this meta-entity, a preintellectual awareness of sorts. If subjectivity affects the understanding of quality, then every attempt to define a general, objective theory or formalization of quality for maps will be unsuccessful.

\section{Concepts of Quality in Economics}

Quality has always been a major concern in business. Here, the meaning of quality can be seen as the ability of a product to serve in a useful capacity, in comparison to other products. This definition of quality consists of both objective, measurable criteria (for example, the chemical purity of an element) and subjective criteria. Such subjective criteria describe the comparative usefulness of similar products in satisfying specific needs. 
The use of the term quality in business is mostly oriented to the needs of the user. An example would be the question of whether the quality of a horse as a transport medium decreased with the invention of automobiles. The ability of a horse to satisfy the needs of a user (to bring him/ her from point $A$ to point $B$ ) is changed in a relative sense. The meaning of quality in this context addresses only the ability of the object to satisfy the particular need, as compared to other products, and has no significance for the individual's perception of an object-subject-relationship (as in the example of the horse rider and the horse).

Such subjective criteria can be recorded by consistently monitoring all parts of a system, as, for example, in Deming's method of improving the quality of whole industries that was influenced by the rivalry between Japanese and American industrial capabilities. Deming (1986) pointed out that a paradigm change from a quantity production-oriented system to a quality production-oriented business system is one of the most reasonable ways of adapting the capabilities of industrial branches. In Deming's view, the key to a continuous improvement in quality is to overcome the so-called "separation beliefs" which assume that isolated decisions and actions could cause general changes in the whole system. By understanding the relationship and complexity between the main influencing parameters of a system, as in the case of industry branches, business, politics, society, or education, a continuous adaption to "better quality" becomes possible.

By understanding cartography as a system, consisting of mapmakers, tools, products and users, similar arguments could apply. To improve the quality of the whole system ("to make maps") the relationships and the context of all determinant parameters have to be monitored.

To answer the question of what a quality map is, cartographers have attempted to define the map's functions. In answering what a good map is, cartographers have discussed map functions and how they might be efficiently carried out. Cartographic definitions of quality fall into different categories:

\section{Maps as pleasing to the eye: Aesthetics and Pleasure}

According to this view (Spiess 1996, Kelnhofer 1996), a major function of maps is their ability to stimulate a form of pleasure. Pleasure, in this sense, has to be seen as the aesthetical form of sensory and non-sensory quality, whether on the level of perceptions, feelings or thoughts. The graphic variables used in cartography (Bertin 1967) are not only important because of their role as a transmitter of quantitative / qualitative information but also because of their role in transporting aesthetical aspects (Tufte 1983, Spiess 1996). Therefore, graphics have to be seen as the tool for stimulating a form of pleasure. If the map fails in this role, it will be judged as "ugly" or of "low quality."

The statement that an Internet-map has "low quality" often arises from this point of view and means that the map does not meet some sort of aesthetical standards. The concern is, therefore, focused on the graphical design and potential of the map. Judgments like this, referring to the poor or missing aesthetical aspects of maps, do not take into consideration the other functions of the map.

Aesthetical aspects are only a part of cartographic quality. The graphics developed by cartographers may be viewed as a continuous improvement to meet the aesthetical and perceptive demands of the map users. Cartographers throughout time have tried to improve their maps, with a major part of these improvements focusing on the aesthetical functions. Research on
"To improve the quality of the whole system ('to make maps') the relationships and the context of determinent parameters have to be monitored."

\section{CARTOGRAPHIC PERSPECTIVES ONQUALITY}

"... a major function of maps is their ability to stimulate a form of pleasure. Pleasure, in this sense, has to be seen as the aesthetical form of sensory and non-sensory quality, whether on the level of perceptions, feelings or thoughts." 
". . the map has high quality when the map transfers

informaton and the user receives the message clearly..."

"The quality of a map, in terms of cognitive quality, has to be judged by its ability to conform to the way maps are mentally processed."

". . a map can be judged as good if it moves into the receiver's mind in such a way that it can be connected with stored knowledge or is stored for future use." perception, graphic variables and map design supports this concern (MacEachren 1995).

\section{Maps as a Communication Device}

By defining a map as a communication device (Robinson 1952, Robinson \& Petchenik 1976), the meaning of quality changes. In this view, the map has high quality when the map transfers information and the user receives the message clearly, i.e., the user receives the message the cartographer has in mind. Therefore, a cartographer would judge a map as good if the user receives the intended information without interference. The graphicalaesthetical aspects are important here as well because of their ability to enhance or interfere with the communication process. For those who view the quality of a map as a communication device, it is, nevertheless, possible to speak of a good map, even if the map is "graphically poorly designed," as long as the information has reached the receiver correctly (Morrison 1978).

If the concept of quality considers the source, object and subject, as do the theories of Deming and Pirsig, then the quality of a map can not be judged by its graphical-aesthetical design alone. By defining graphical design, it becomes a suitable means to reach improved quality.

\section{Processing Maps in the Mind: Cognitive Quality}

The quality of a map, in terms of cognitive quality (Peterson 1994), has to be judged by its ability to conform to the way maps are mentally processed. In Peterson's opinion, maps are internalized in some way and are connected to former and future knowledge. At a later time, the stored mental image or information stored in non-image form can be used. The mental processing of maps is described as interactive, dynamic, multimedial, and multidimensional, consequently, Peterson rates the quality of maps in terms of their similarity to these attributes. The recent technological innovations like interactivity, multimedia and animation are, therefore, helpful steps in improving the quality of maps because of their greater similarity to the mental processing of maps.

According to this view, a map can be judged as good if it moves into the receiver's mind in such a way that it can be connected with stored knowledge (mental maps) or is stored for future use. The map's primary function, then, is not to be found in the production, presentation or immediate reception, but in how it helps our mental processing of spatial information. Therefore, it is possible that graphically poorly designed maps can be seen as having high quality. In fact, the quality of a map cannot be determined until long after it has been used.

Furthermore, proponents of this view extend the meaning of quality from beyond the actual communication process to the impacts and consequences that the map's information has for the mental processing of spatial information. This could help to overcome one of the weaknesses of information theory associated with cartographic communication, by explaining how knowledge can be acquired by the receiver that the sender had not intended.

Using this definition, the meaning of quality is not only expanded, but an adequate explanation of the new cartographic products that have resulted from the use of technologies such as interactive maps, multimedia, computer-animation or hypermedia can be given. Earlier concepts of quality in cartography often cannot judge the quality of these new cartographic expressions. By using the concept of "cognitive quality," a more adequate evaluation of these new cartographic expressions becomes possible. 


\section{The GIS Approach}

Cartography has been intensely influenced by the development and use of geographic information systems (GIS). With such a powerful influence on the cartographic community, the development of GIS has led to different ways of viewing the meaning of quality and enhancing the analytical potential and usage of maps.

For GIS, a map is a derivation of an abstract and scale-less ("primary") model of a part of the world (Bartelme 1995, Maguire \& Dangermond 1991). Therefore, the quality of a map has to be seen not only in its ability to meet the aesthetical and informational demands of the user but also in its ability to meet the technological needs of the GIS-system. As a consequence, quality, according to this view, is a measure of how well the map ("secondary model") is derived from the model and how well it meets the demands of the system in terms of supporting the presentation and visualization tasks (Bill 1994, Mark \& Frank 1995).

The secondary model requires the use of generalization methods. Many doubt that general formalization algorithms for an automatic derivation of maps from a primary model can be found (Kelnhofer 1996). Therefore, this major aspect of the understanding of the quality of a map in context with GIS, the quality of derivation, can be seen as using absolute concepts by defining a highest goal ("formalized and automated derivation"), to which we should aspire.

\section{The Visualization Approach}

Geographic visualization (Gvis), as formulated by DiBiase (1990) and MacEachren (1994), has to be seen in close relationship to the development of computer graphic data processing. In this approach, the functions of a map can be divided into presenting, communicating, analyzing and exploring spatial data. The definition of quality is, therefore, extended to the ability and capacity of a map to lead to more questions. By extending the definition to include the ability to interact with a map (as a result of technological development), maps have not only the function to present something known but also to make something unknown perceivable and knowable.

Understanding quality according to this approach has to be seen as technology-oriented and usage-oriented. Technology-oriented because geographic visualization demands that maps have specific abilities and characteristics such as interactivity and dynamic processing, and usageoriented because the quality of a map is judged by its ability to enable "visual thinking" and to meet the needs (explanation, confirmation, synthesis and presentation) and interests of the user, whether private or public.

This usage-orientation of geographic visualization implies "some connotations" (MacEachren 1995, p. 452). MacEachren has noted that by trying to define the goal of visualization as making presentations as pictorial as possible ("moving toward realism"), implications for the interaction between scientists and the society can be expected. The potential of "scientific representations more like the real world" (p.452) at the societal level, in terms of becoming public, can be seen as another approach to the meaning of quality in the context of cartography.

The recent developments in cartography, driven by technological innovations, have led to new forms of cartographic expression and to new cartographic products. The common definitions and understanding of quality
"... quality, ... is a measure of how well the map is derived from the model and how well it meets the demands of the system in terms of supporting the presentation and visualization tasks."

"The definition of quality is, ... extended to the ability and capacity of a map to lead to more questions." 
"Maps on computer screens cannot compare with paper maps in their graphical resolution; nevertheless, they can have higherquality."

"In pursuing the goal of cartography to make 'better' maps, it is ... important... to understand and comprehend what 'better' means."

ACKNOWLEDGMENTS

REFERENCES may not be useful in judging these new forms of mapping. This assessment should not be misinterpreted as a justification for lower quality maps on the Internet where suitable methods are developed to fit the needs (and deficiencies) of technology, but should be seen as an attempt to find appropriate and fair judgment criteria.

To further develop the understanding of quality, theories in both philosophy and business offer sophisticated concepts and ideas that can lead to a better understanding of the meaning of quality in cartography as well. In this context, it is necessary to realize that the definition of quality changes with time, space, and social context. Cartography is also dynamic. A statement such as "this map is a quality map" has different meanings with changing time, space or social context, and has, therefore, to be seen as both a statement about the perception of the user and as a statement about the map. This suggests that any improvement in quality must take this view into consideration.

Cartographers often use deontological (concerning the rules) forms of thinking when considering the quality of maps. By considering the goals and the consequences of an action (the map) in a teleological (concerning the goals) way of thinking (like the cognitive quality approach by Peterson or the visualization approach by MacEachren), actions (maps) would be valued that tend to promote the realization of the right goals as good, and the realization of bad goals as bad.

Maps on computer screens cannot compare with paper maps in their graphical resolution; nevertheless, they can have higher quality. For some cartographers, this statement is problematical. It may become more acceptable if the term quality is replaced with the term value, as Pirsig suggests. DiSanto \& Steele (1990) make the same point when they note that: "I can understand that a Ford Taurus may be a better value than a Rolls Royce, but I have a hard time seeing it as having greater quality."

In pursuing the goal of cartography to make "better" maps, it is not only important to adapt, develop and monitor cartographic techniques, algorithms, methods and theories but to understand and comprehend what "better" means.

This paper would not have been written without the intellectual and organizational help of Mike Peterson, who hosted me during my Fulbrightgrant in the Fall semester of 1997 at the Department of Geography / Geology at University of Nebraska at Omaha. The comments of Cynthia Brewer, William Cartwright, Andrew Frank, Alan MacEachren, Mark Monmonier and Judy Olson have been very helpful. Finally, I want to thank Kathy Peterson for her highly appreciated help of improving the "Austrian way of writing English."

Bartelme, N. (1995) Geoinformatik, Springer, Berlin-Heidelberg.

Bill, R. (1994) "Multimedia GIS - definition, requirements and applications," The 1994 European GIS yearbook, pp. 151 - 154.

Crampton, J. (1995) "The ethics of GIS," Cartography and GIS, 22, 1, pp. 84 89.

Crampton, J. (1997) "Cartography, GIS and the Web," presentation to the NACISXVII, Lexington, KY.

DiBiase, D.W. (1990) "Visualization in the earth sciences," Earth and Mineral Sciences, 59, 2, pp. 13 - 18. 
Dickmann, F. (1997) "Kartographie im Internet," Kartographische Nachichten, 47,3, pp. $87-96$.

DiSanto, R. \& T. Steele (1990) Guidebook to Zen, Morrow, New York.

Deming, W.E. (1986) Out of the Crisis, MIT Center for Advanced Engineering Study, Cambridge.

Dobyns, L. \& C. Crawford-Manson (1994) Thinking About Quality, Random House, New York.

Gartner, G. (1996) "Internet für Kartographen," Kartographische Nachrichten, 46,5 , pp.185-190.

Green, D. (1997) "Cartography and the Internet," The Cartographic Journal, 34,1, pp. 23-27.

Hansen, H.R. (1996) Klare Sicht am Info-Highzay, Orac, Wien.

Harley, J.B. (1991) "Can there be a cartographic ethics?," Cartographic Perspectives, 10, pp.9-17.

Harrower, M. \& C.P. Keller, D. Hocking (1997) "Cartography on the Internet: Thoughts and a preliminary user survey," Cartographic Perspectives, 26, pp. 27-37.

Imhof, E. (1969) Kartographische Geländedarstellung, De Gruyter, Berlin.

Kelnhofer, F. (1996) "Geographische und/oder Kartographische Informationssysteme," Beiträge zum Kartographiekongreß lnterlaken, SGK, 14, pp. 9-27.

MacEachren, A.M. (1994) "Visualization in modern cartography: setting the agenda" in MacEachren, A. \& F.D.R. Taylor (eds.), Visualization in Modern Cartography, Pergamon, Oxford, pp. 1 - 13.

MacEachren, A.M. (1995) How Maps Work, Guilford Press, New York.

Maguire, D. \& J.Dangermond (1991) "The functionality of GIS" in Maguire, D. \& M.Goodchild, D.Rhind (eds.), Geographical Information Systems, Longman.

Mark, D. \& A. Frank (1995) "Experiential and Formal Models of geographic space" in Campari, I. \& A. Frank (eds.), Experiential Realism and its Applications to Geographic Space, Department of Geoinformation, TU Vienna, pp.432.

McHaffie, P. (1990) "Contribution to ethical problems in Cartography Roundtable Commentary," Cartographic Perspectives, 16, pp.3-13.

Monmonier, M. (1991) How to Lie with Maps, University of Chicago Press, Chicago.

Morrison, J. (1978) "Towards a functional definition of the science of cartography with emphasis on map reading," The Anerican Cartographer, 5, pp. $97-110$. 
Muehrcke, P. (1990) "Cartography and GIS," Cartography and GIS, 17, 1, pp. $7-15$.

Müller, J.C. (1997) "GIS, Multimedia und die Zukunft der Kartographie," Kartographische Nachrichten, 47, 2, pp. 41 - 51.

Peterson, M. (1994) "Cognitive issues in cartographic visualization" in MacEachren, A. \& F.D.R. Taylor (eds.), Visualization in Modern Cartography, Pergamon, Oxford, pp. 27 - 45.

Peterson, M. (1995) Interactive and Animated Cartography, Prentice Hall, Englewood Cliffs.

Peterson, M. (1997) "Cartography and the Internet: Introduction and Research Agenda," Cartographic Perspectives, 26, pp. 3 - 12.

Pirsig, R. (1974) Zen and the Art of Motorcycle Maintenance, Morrow, New York.

Robinson, A. (1952) The Look of Maps, University of Wisconsin Press, Madison.

Robinson, A. \& B. Petchenik (1976) The Nature of Maps, University of Chicago Press, Chicago.

Spiess, E. (1996) "Attraktive Karten - ein Plädoyer für gute Kartengrafik," Beiträge zum Kartographiekongreß Interlaken, SGK, 14, pp. 57 - 73.

Taylor, F.D.R. (1994) "Perspectives on Visualization and Modern Cartography" in MacEachran, A. \& F.D.R. Taylor (eds.): Visualization in Modern Cartography. Pergamon, Oxford, pp. $333-341$.

Tufte, E.R. (1983) The Visual Display of Quantitative Information, Graphics Press, Cheshire. 